\title{
Article
}

\section{On Modeling the Cost of Ownership of Plug-In Vehicles}

\author{
Karim Hamza *(D), Kenneth P. Laberteaux and Kang-Ching Chu (i) \\ Toyota Motor North America R\&D, Ann Arbor, MI 48176, USA; ken.laberteaux@toyota.com (K.P.L.); \\ jean.chu@toyota.com (K.-C.C.) \\ * Correspondence: karim.hamza@toyota.com; Tel.: +1-734-546-2423
}

\section{check for} updates

Citation: Hamza, K.; Laberteaux, K.P.; Chu, K.-C. On Modeling the Cost of Ownership of Plug-In

Vehicles. World Electr. Veh. J. 2021, 12, 39. https://doi.org/10.3390/ wevj12010039

Received: 21 January 2021

Accepted: 18 February 2021

Published: 9 March 2021

Publisher's Note: MDPI stays neutral with regard to jurisdictional claims in published maps and institutional affiliations.

\begin{abstract}
Plug-in vehicles (PEVs), which include battery-only electric vehicles (BEVs) and plug-in hybrid electric vehicles (PHEVs), have steadily grown in sales amidst various incentive programs, but much speculation exists on when PEVs would become cost-competitive without incentives. This research adopts a bottom-up approach for estimation of purchase cost, and total cost of ownership (TCO). Baseline predictions, as well as sensitivity analysis (with more favorable conditions for PEVs) are generated for 2030. Results show that the five-year TCO of some PEVs could be less than an equivalent-sized conventional internal combustion-engine (CICE) vehicle, but only in the more optimistic scenarios where the cost of batteries and motors decrease more rapidly than the baseline prediction, and when combined with either higher gasoline prices or longer annual distance travelled. However, without subsidies or incentives, purchase cost parity between PEVs and CICEs was not realized in any of the considered 2030 scenarios.
\end{abstract}

Keywords: PHEV (plug in hybrid electric vehicle); EV (electric vehicle); purchase cost; total cost of ownership

\section{Introduction \\ 1.1. Background and Related Work}

Plug-in vehicles (PEVs) refer to a subset of electric drive vehicles [1] that have sufficiently large traction battery and the capability to charge it via grid electricity, resulting in an appreciable fraction of the vehicle miles travelled (VMT) being powered by grid electricity. Although PEVs include battery-only electric vehicles (BEVs), plug-in hybrid electric vehicles (PHEVs) and plug-in fuel-cell electric vehicles, this paper only focuses on PHEVs and BEVs. In addition to the higher efficiency of electric drive compared to conventional internal combustion-engine (CICE) vehicles, utilizing grid electricity for a large portion of VMT can (depending on grid generation mix) lead to a large reduction of greenhouse gas (GHG) emissions [2-6], which is a key desirable societal benefit.

Sales of PEVs have mostly seen steady growth in the US [7] in the presence of various incentive programs that include tax credits [8], purchase rebates [9], as well as other perks such as access to high-occupancy vehicle (HOV) highway lanes [10]. Much speculation exists on when/whether PEVs would/could be cost competitive in the mass market without any incentives. Two important metrics in assessing cost competitiveness include: (i) purchase cost to a prospective owner, and (ii) total cost of ownership (TCO), which also factors in a resale value and running costs throughout a period of ownership. While [11] shows that reducing GHG emissions via PEVs comes at an increased cost compared to CICEs, [12] predicts that BEVs could reach TCO parity, and even purchase cost parity with CICEs by the mid-2020s. In general, bottom-up approaches for cost estimation follow the same framework of: (i) estimation of the cost of technologies/components to manufacture the vehicle, (ii) estimation of mark-ups pertaining to vehicle acquisition, and (iii) estimation of costs and/or credits throughout the vehicle ownership period. Depending on assumptions and/or cost forecasting models of various components, similar frameworks could lead to very different results. To help resolve some of those uncertainties in a 
transparent manner, the authors conducted an extensive review / critique of the literature and publicly available data sources [13], with the culmination of the work open-sourced into a publicly-accessible spreadsheet [14].

\subsection{Objective and Contributions}

The objective of this work is to provide transparent and updated cost models for prediction of purchase and total cost of ownership of PEVs, and to apply such models to predictions through 20203.

One contribution of this work is to provide a cautionary note that some of the recent publications seeking to address the same question (which are predicting price parity between PEVs and CICEs by mid-2020s) may be overly optimistic. Furthermore, by providing all calculations as an open-source spreadsheet, the research community at large may revise assumptions and/or examine other future scenarios.

\subsection{Organization of the Manuscript}

The manuscript started with a brief background and overview of related work, which led to the scoping of the objective. The rest of the manuscript is organized as follows: Section 2 provides an overview of the various elements of the cost modeling as well as showing the results for the "baseline" scenarios of purchase cost and TCO. Section 3 then considers various sensitivity analyses, including more rapidly improving costs of electrification technologies, more expensive gasoline, as well as differences in typical driving and transportation needs across fewer/more urban vehicle owners. Section 4 concludes the manuscript with a summary of main findings and some consideration of future development.

\section{Cost Modeling and Baseline Scenario}

This section provides an overview summary of the cost model and the adopted inputs/assumptions. For a more detailed review and critique of the literature and data sources, interested readers may refer to [13]. The main categories of the bottom-up cost model are:

- Cost to build the vehicle. This includes cost estimates and forecasting for the vehicle powertrain, which (depending on vehicle powertrain type) includes several subsystems such as the engine, battery, motor, transmission and/or on-board charger. This category also includes direct cost for the rest of the vehicle (assumed to be approximately the same irrespective of the powertrain type), as well as indirect cost that accounts for various overheads (such as administration, equipment amortization/depreciation, research and development, ... etc.)

- Mark-ups pertaining to vehicle acquisition. This includes Original Equipment Manufacturer (OEM) profit margin, dealer costs and profit margin, purchase tax, as well as costs for a home charger in case of first time PEV buyers.

- Cost and credits throughout the ownership period. Excluding various forms of incentive (since current analysis is focused on cost competitiveness without incentives), this includes running costs for fuel and/or electricity, registration and insurance, periodic maintenance, as well as a resale value at the end of ownership period. In the case of BEVs, there could also be additional cost for a "replacement vehicle" (assumed to be a CICE) on days when the travel need exceeds the BEV range.

Some details of the cost elements are provided as follows:

- Direct cost of vehicle without powertrain was estimated at $\$ 12,700$ for non-BEV and $\$ 12,600$ for BEV per the tear-down report in [15], but this cost is increased (per the assumptions in [12]) by $6 \%, 5 \%$ and $21 \%$ for vehicle size categories in the US of Car, Crossover and Sport Utility Vehicle (SUV), respectively.

- Cost of battery system, which includes the cells, connectors, packaging, and thermal management, had some variation in estimated cost for 2018 in the literature surveyed in [13]. As such, a cost value for $2016 \mathrm{BEV}$ batteries ( $\$ 273 / \mathrm{kWh}$-pack), for-which there 
is better agreement in the literature, was projected to an estimated 2030 cost value from [16] ( $\$ 108 / \mathrm{kWh}$-pack) at a fixed annual percentage reduction. Further details about battery system costs include:

- PHEV batteries are $20 \%$ more expensive than BEV batteries in terms of $\$ / \mathrm{kWh}$ at the pack level, as per the assumption in [12].

- Sizing of a battery pack to achieve a desired electric driving range depends on both the energy efficiency of a vehicle, as well as the battery swing (ratio of usable battery energy between charging/discharging limits to nominal capacity). Typical vehicle energy efficiency for 2018 and expectations for 2030 were adopted from [12]. On the other hand, battery swing is estimated to be $76 \%$ for PHEVs and $96 \%$ for BEVs, per typical vehicles in [17].

- Cost of motor system, which includes the motor, controller and power electronics, had much variation in the estimated cost for 2018 in the reviewed literature in [13]. An attempt at calibrating a regression model (from publicly available retail prices data) in [13] led to the adoption of a first-order cost model of $\$ 300$ plus $\$ 22.3 / \mathrm{kW}$ of motor power. The motor system is understood to be relatively mature technology and as such, the costs are assumed to be getting reduced by only $1 \%$ annually up to 2030 , per [18].

- Cost of the engine system, which includes the engine, air intake system, fuel system, controller, and exhaust system is also estimated via a first-order model (from [19]) of $\$ 845$ plus $\$ 21.3 / \mathrm{kW}$ of engine power. With engine technologies being mature, it is assumed that technology development efforts towards cost reduction are counterbalanced by the need to improve fuel economy, thereby resulting in no significant change in cost of the engine system between 2018 and 2030.

- Cost of the transmission system makes a distinction between the multi-speed or continuous-variable speed gearboxes used in CICEs and PHEVs, versus the singlespeed reducers that are typically used in BEVs. With very limited publicly available data, a regression modelling approach in [13] resulted in cost estimates of $\$ 580$ plus $\$ 14.6 / \mathrm{kW}$ for multi-speed or continuous-variable speed gearboxes, and $\$ 670$ plus $\$ 3.8$ for single-speed reducers. Similar to the engine system, transmission systems are treated as a mature technology, with no significant cost changes expected between 2018 and 2030.

- The charging system includes the on-board charger and cables for PEVs, which are considered as part of the powertrain cost and are estimated at \$423 per [15]. The charging system also includes acquisition and installation of a home charger for firsttime PEV buyers. A home charger is not considered part of the powertrain cost but is part of the total purchase cost. As per the data sources surveyed in [13], the cost for a (Level-1) home charger for PHEVs is modelled at \$300, while cost of a (Level-2) charger for BEVs is modelled at $\$ 1854$. Similar to the motor system, charging system costs are estimated to decline in cost by only $1 \%$ annually up to 2030 .

- Indirect cost in 2018 is estimated (per [15]) at 20.5\% for mass-market CICEs and at $40 \%$ for BEVs since they include newer technologies and are produced in limited volume. In current work, PHEVs in 2018 are assumed to have the same indirect cost as BEVs, while all PEVs are expected to tend towards the same indirect cost of mass-market CICEs (i.e., $20.5 \%$ ) by 2030.

- Other mark-ups include OEM profit margin, which (per [12]) are assumed to be 5\%, $10 \%$ and $15 \%$ for Car, Crossover and SUV respectively. In addition, the total purchase cost also considers $15 \%$ dealer mark-up (dealer operating costs and profit margin) and $8.5 \%$ purchase tax.

- Fuel/electricity costs depend on the vehicle efficiency in [gal/mile] and/or [kWh/mile], annual VMT, as well as the ratio of electric-VMT to total VMT, which is known as the utility factor (UF). In [13] and current work, real-world travel data from the California household travel survey (CHTS) [20] is utilized for calculation of the UF for population average, as well as for sub-groups of vehicles that are "less urban" or "more urban" 
(per clustering analysis in [21]), as summarized in Table 1. For BEVs, the fraction of non-electric miles (on days when travel need exceeds the BEV range) are assumed to be done on a "replacement vehicle" that is a CICE of the same size class, and thus, BEVs may incur "gas cost". The replacement vehicle is assumed to be a second household vehicle, and thus its usage cost (besides gas consumption) is assumed at a fairly low rate of $\$ 0.58 / \mathrm{mile}(\$ 0.36 / \mathrm{km}), \$ 0.62 /$ mile $(\$ 0.39 / \mathrm{km})$ and $\$ 0.65 / \mathrm{mile}$ $(\$ 0.40 / \mathrm{km})$ for Car, Crossover and SUV, respectively. The cost of gas and electricity are obtained from statistics/predictions by the US Energy Information Administration (EIA) [22,23]. Average gas cost in 2018 was $\$ 2.81 /$ gal $(\$ 0.74 / \mathrm{L}$ ) and its baseline 2030 prediction is $\$ 3.36 /$ gal $(\$ 0.89 / \mathrm{L}$ ), while average electricity cost was $\$ 0.128 / \mathrm{kWh}$ in 2018 and is predicted to be $\$ 0.130 / \mathrm{kWh}$ in 2030 .

- Annual registration and insurance costs are assumed to be the same for all powertrains (and are thus irrelevant in cost comparisons) but are included for completeness. The estimates are $\$ 285 /$ year for registration [24], and $\$ 887 /$ year for insurance [25].

- Maintenance costs in [13] are based on a report from the American Automobile Association (AAA) [26]. For CICEs, the costs are estimated at $\$ 0.085 / \mathrm{mile}(\$ 0.053 / \mathrm{km})$, $\$ 0.091 / \mathrm{mile}(\$ 0.056 / \mathrm{km})$ and $\$ 0.096 / \mathrm{mile}(\$ 0.060 / \mathrm{km})$ for Car, Crossover and SUV respectively, while BEV Car maintenance costs are estimated at $\$ 0.066 /$ mile $(\$ 0.041 / \mathrm{km})$. Due to lack of maintenance data for BEV Crossover and SUV, the cost for a BEV Car is scaled proportionally using the ratios of CICE. PHEVs are assumed to have the same maintenance costs as CICEs.

- $\quad$ Re-sale value after five years for a number of CICEs, PHEVs and BEVs at different zip codes was sampled in [13] using data from the Kelly Blue book [27]. The average resale value was observed to be approximately $51 \%$ of the vehicle original value for CICEs and PHEVs. On the other hand, resale value for BEVs was approximately $40 \%$ of the vehicle original value.

Table 1. Annual vehicle miles travelled (VMT) and utility factor (UF) based on California household travel survey (CHTS) dataset.

\begin{tabular}{|c|c|c|c|c|}
\hline & & \multicolumn{3}{|c|}{ CHTS Dataset Vehicle Samples } \\
\hline \multicolumn{2}{|c|}{-} & All CHTS & $29 \%$ Least Urban & 29\% Most Urban \\
\hline \multicolumn{2}{|c|}{$\begin{array}{l}\text { Average Annual VMT (mile/year) } \\
(\mathrm{km} / \text { year })\end{array}$} & $\begin{array}{c}13,250 \\
(21,319)\end{array}$ & $\begin{array}{c}18,144 \\
(29,194)\end{array}$ & $\begin{array}{c}6944 \\
(11,173)\end{array}$ \\
\hline \multirow{5}{*}{ Utility Factor [\%] } & PHEV50-Parallel & $72.6 \%$ & $61.9 \%$ & $93.9 \%$ \\
\hline & PHEV50-Serial & $72.6 \%$ & $61.9 \%$ & $93.9 \%$ \\
\hline & BEV150 & $81.4 \%$ & $70.9 \%$ & $99.1 \%$ \\
\hline & BEV200 & $88.1 \%$ & $81.3 \%$ & $99.8 \%$ \\
\hline & BEV250 & $92.2 \%$ & $89.0 \%$ & $100.0 \%$ \\
\hline
\end{tabular}

Using those cost values, purchase cost and TCO in 2018, as well as a baseline scenario for 2030 are constructed and shown in Figure 1. An extension beyond the work in [13] includes some distinction between serial and parallel drive PHEVs. In [13] and the current study, the powertrain rated power (engine peak power for CICEs and motor peak power for BEVs) is $150 \mathrm{~kW}$ for Car and Crossover, and $220 \mathrm{~kW}$ for SUV, similar to [12]. In general, the engine of a PHEV is sized for average power demand (not peak power demand) and thus, PHEVs engine power is modelled at $70 \%$ of the rated powertrain power (per typical PHEV models on the market [17]). The distinction between serial and parallel drive PHEVs is primarily that a serial drive has no direct power flow path between engine and wheels, and thus its motor is sized similar to an equivalent BEV. On the other hand, a parallel-drive PHEV can have both engine and motor simultaneously providing power to the wheels during instances of high-power demand. This allows for down-sizing of the required motor power while maintaining the same vehicle handling performance. In several real-world 
parallel drive PHEVs (as well as regular hybrids) [17], the motor power is less than the engine power. In current work, however, we assume that the motor power matches the engine power (i.e., $70 \%$ of the powertrain rated power) for parallel-drive PHEVs. For that reason, the parallel-drive PHEV appears to have a small cost advantage (owing to reduction in motor cost) compared to the serial-drive PHEV in Figure 1. Further distinctions between serial and parallel drive PHEVs include: (i) the parallel drive allows better optimization of motor operating point (especially in highway travel), and thus improving overall efficiency of the vehicle and reducing running cost, and (ii) the transmission for serial drive PHEV can be as simple as that of BEV (in fact, some serial-drive PHEV models are referred to as an "electric vehicle with range extender"), thus allowing reduction of the powertrain cost. However, accounting for the two latter distinctions between serial and parallel drives requires further data/detail than what is available in current model and, thus, is beyond the scope of this paper.

As a notation in current work, numeric annotation of a PEV model is an indicator of its electric range in miles. For example, PHEV50 implies a PHEV with 50 miles of electric range, while BEV200 implies a BEV with a range of 200 miles. Main observations from the baseline scenario shown in Figure 1 include:

- The cost of PEV powertrains (Figure 1a) appeared to be dominated by battery costs in 2018, with the lowest PEV powertrain cost (for parallel-drive PHEV50) being approximately $\$ 7000, \$ 8000$ and $\$ 11,200$ more than CICE in the size categories of Car, Crossover and SUV, respectively. Battery cost predictions in 2030 bring the difference in powertrain costs closer, with the lowest PEV powertrain cost (BEV150) at approximately $\$ 1800, \$ 2500$ and $\$ 3500$ more than CICE for Car, Crossover and SUV respectively.

- With the cost of PEV powertrains being higher than that of CICE, and with all markups being approximately the same, the purchase cost of all PEVs remains higher than CICE in 2030 for all size categories (Figure 1b). This includes the assumption that the indirect cost of all PEVs becomes the same as CICEs by 2030.

- Running cost of most PEVs (except BEV150) is lower than corresponding CICE (Figure 1c). While BEVs have lower maintenance cost compared to PHEVs, BEVs incur additional cost for a replacement vehicle for the non-electric fraction of VMT per their UF, resulting in PHEVs having overall lower running cost. Since UF, and by extent, the running cost, can vary significantly depending on vehicle usage pattern, in the upcoming sensitivity analysis section, VMT and UF values (Table 1) corresponding to less urban and more urban sub-groups of vehicle samples in the CHTS dataset will also be considered.

- Another notable observation about running cost is that the increase in unit price of gasoline and electricity for baseline 2030 scenario is mostly counter-balanced by improvements in vehicle efficiency across all powertrain types (per predicted vehicle efficiency values in [12]), resulting in no significant change in cost of gasoline and electricity between 2018 and 2030 for all powertrain types.

- Combining purchase cost and running cost over five years, then accounting for vehicle resale, allows for estimation of TCO (Figure 1d). Although most PEVs have lower running cost than CICE, and despite the gap in purchase cost being relatively small for the baseline 2030 scenario, savings in running cost over five years are insufficient to offset the difference in purchase cost in any of the studied vehicle size categories. 
(a) Powertrain Cost

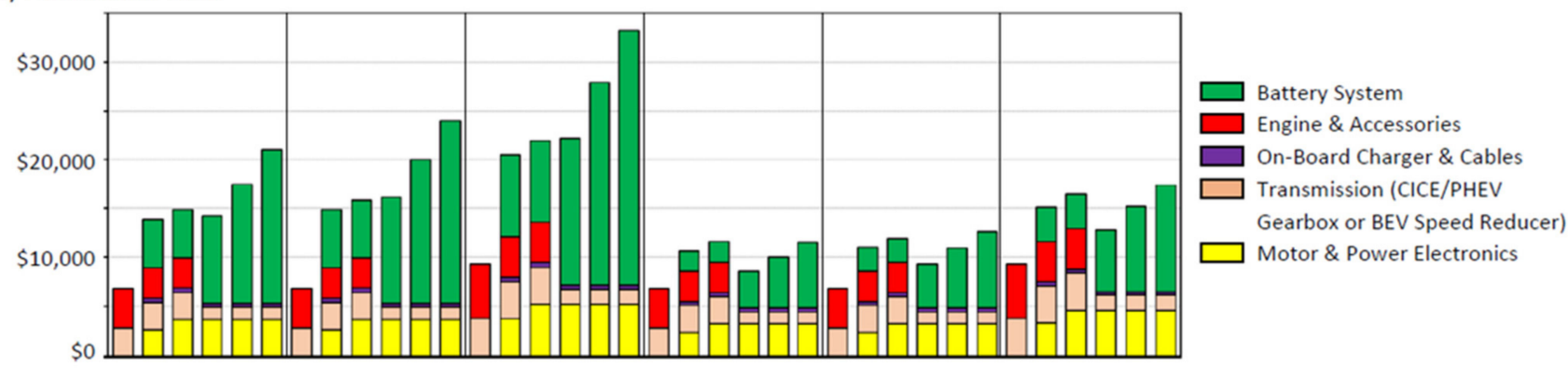

(b) Purchase Cost
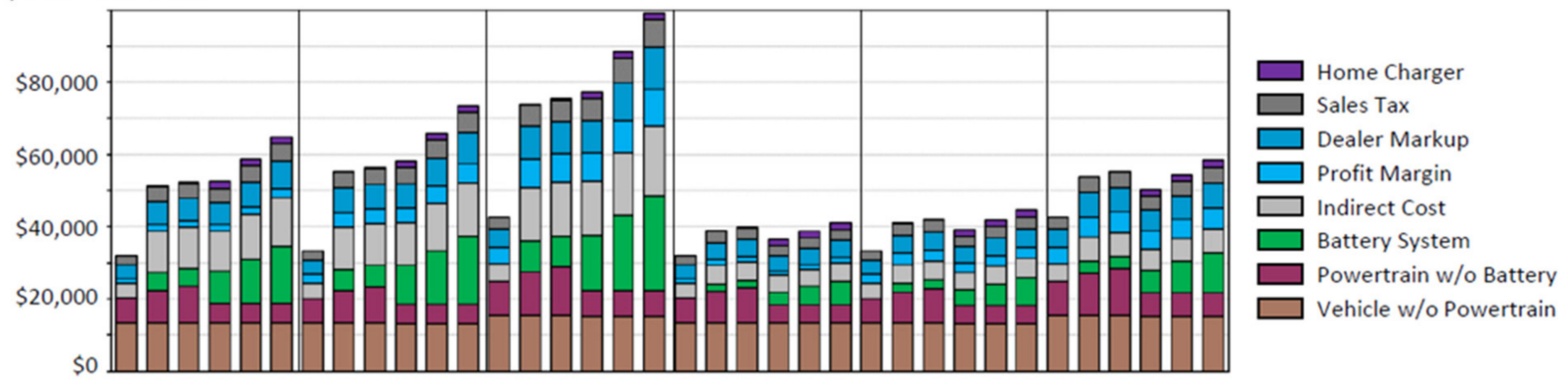

(c) Annual Running Cost

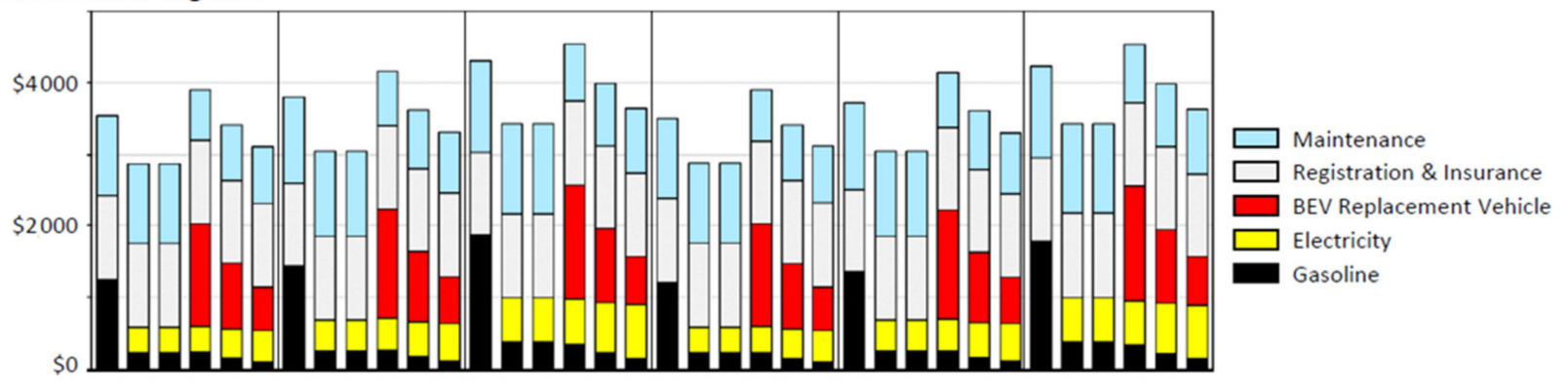

(d) Five-Year Total Cost of Ownership

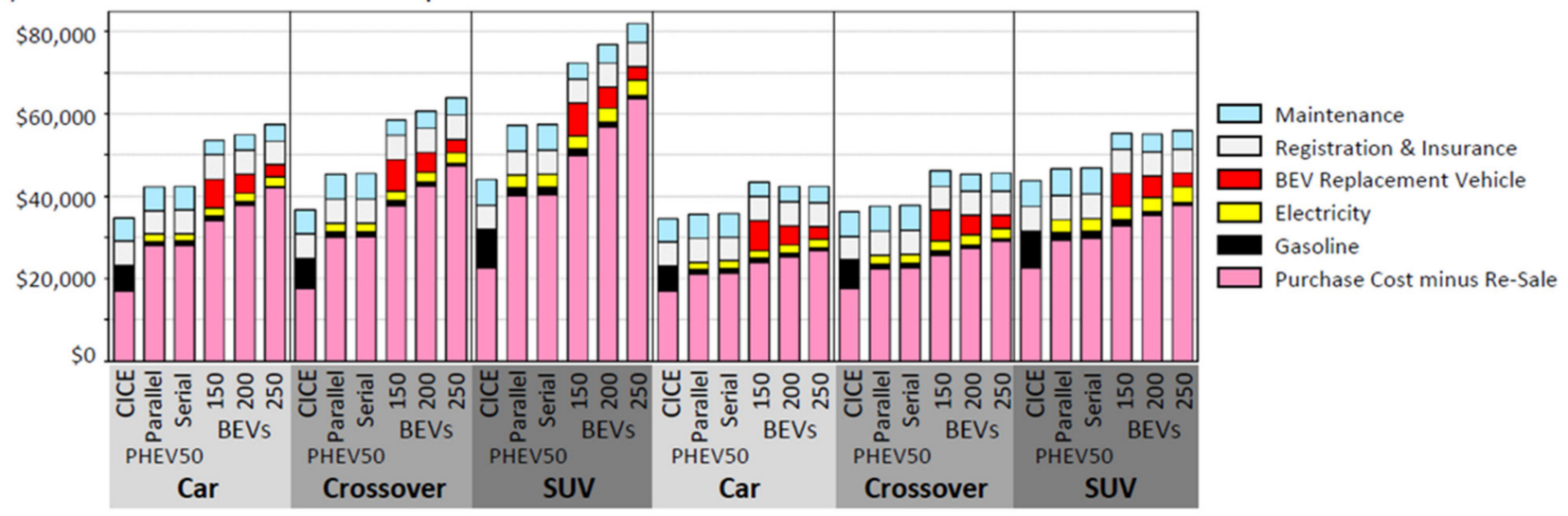

Figure 1. Baseline estimated costs of conventional internal combustion-engine (CICE) and various plug-in vehicle models for 2018 and 2030. (a) Cost of powertrain Only (b) Total purchase cost of the vehicle (c) Annual running cost of the vehicle (d) Total cost of ownership over five years (purchase cost plus running cost minus resale value).

\section{Sensitivity Analysis}

The publicly open sourced spreadsheet [14] developed as a culmination of the cost modeling includes several tabs, with the summary tab including a section that allows for sensitivity analysis, as shown in Figure 2. Aside from the previously discussed baseline 
scenario, the current work also considers (what is perceived to be) bounds for optimistic scenarios that are more favorable for PEVs. The optimistic scenarios include:

- Motor system (i.e., motor and power electronics) costs that are $20 \%$ less expensive than the 2030 baseline (which had assumed 1\% annual cost reduction from 2018 to 2030), which is perceived to be an optimistic since motor technology is fairly mature. This adjustment is made by setting the value of the spreadsheet cell B3 (Figure 2) to a value of 0.8

- Battery system costs $20 \%$ less expensive than the 2030 baseline (which had assumed $\$ 108 / \mathrm{kWh}$ for BEV battery packs), implying $\$ 86 / \mathrm{kWh}-$ pack, which is likely a bounding limit barring new battery technology getting discovered, since to the best of the authors' knowledge at the time of writing this manuscript, no OEM has made any official announcement regarding battery packs at less than $\$ 100 / \mathrm{kWh}$. This adjustment is made by setting the value of the spreadsheet cell B2 (Figure 2) to a value of 0.8

- More expensive gasoline in 2030 by selecting the upper-bound prediction from [23], which is $\$ 5.1 /$ gal $(\$ 1.35 / \mathrm{L})$. This adjustment is made by setting the value of the spreadsheet cell B5 (Figure 2) to a value of 2.

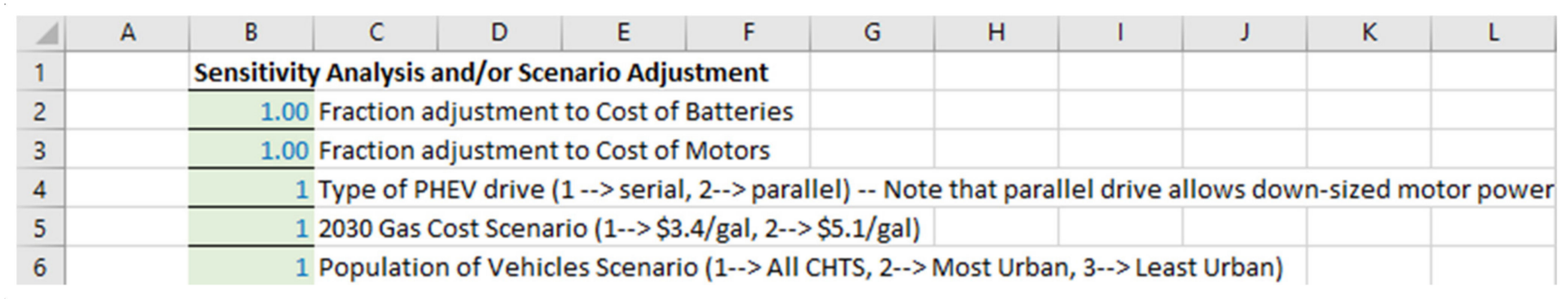

Figure 2. Excerpt from the spreadsheet in [14] showing spreadsheet cells controlling sensitivity analysis.

In addition to adjustment of motor, battery and costs, the sensitivity analysis in this section considers different annual VMT and UF corresponding to different vehicle usage patterns. This is done by setting the value of the spreadsheet cell B6 (Figure 2) to a value of $\{1,2$ or 3$\}$ for vehicle sub-populations corresponding to CHTS sample subsets (a shown in Table 1) of all CHTS, most urban and least urban, respectively.

Since vehicle driving patterns and cost of gasoline affect the running cost (and by extent, TCO) but not purchase cost, the more optimistic purchase cost scenarios in current work consider: (i) the less-expensive motor system, (ii) less-expensive battery system, and (iii) less-expensive motor and battery systems, as shown in Figure 3. As a note about Figure 3, line plots are utilized for providing good visualization of the contrast between 2018 and 2030 (for example, difference in purchase cost from 2018 to 2030 for BEV250 Car is more difficult to eyeball in Figure 1b) but should not be interpreted as interpolation between 2018 and 2030 (since [14] only estimates cost values for 2018 and 2030). To aid in distinction between various scenarios, Figure 3 also includes zoom-in magnification (area surrounded by blue boxes in Figure 3) of the 2030 cost estimates. The main observation from Figure 3 is that even in the most optimistic cost of technology scenarios (both Motor and Battery systems at $20 \%$ less than baseline), the least purchase cost PEV (which is BEV150 in 2030) is at approximately $\$ 2300, \$ 3200$ and $\$ 3800$ more than CICE for the size categories of Car, Crossover and SUV, respectively. 


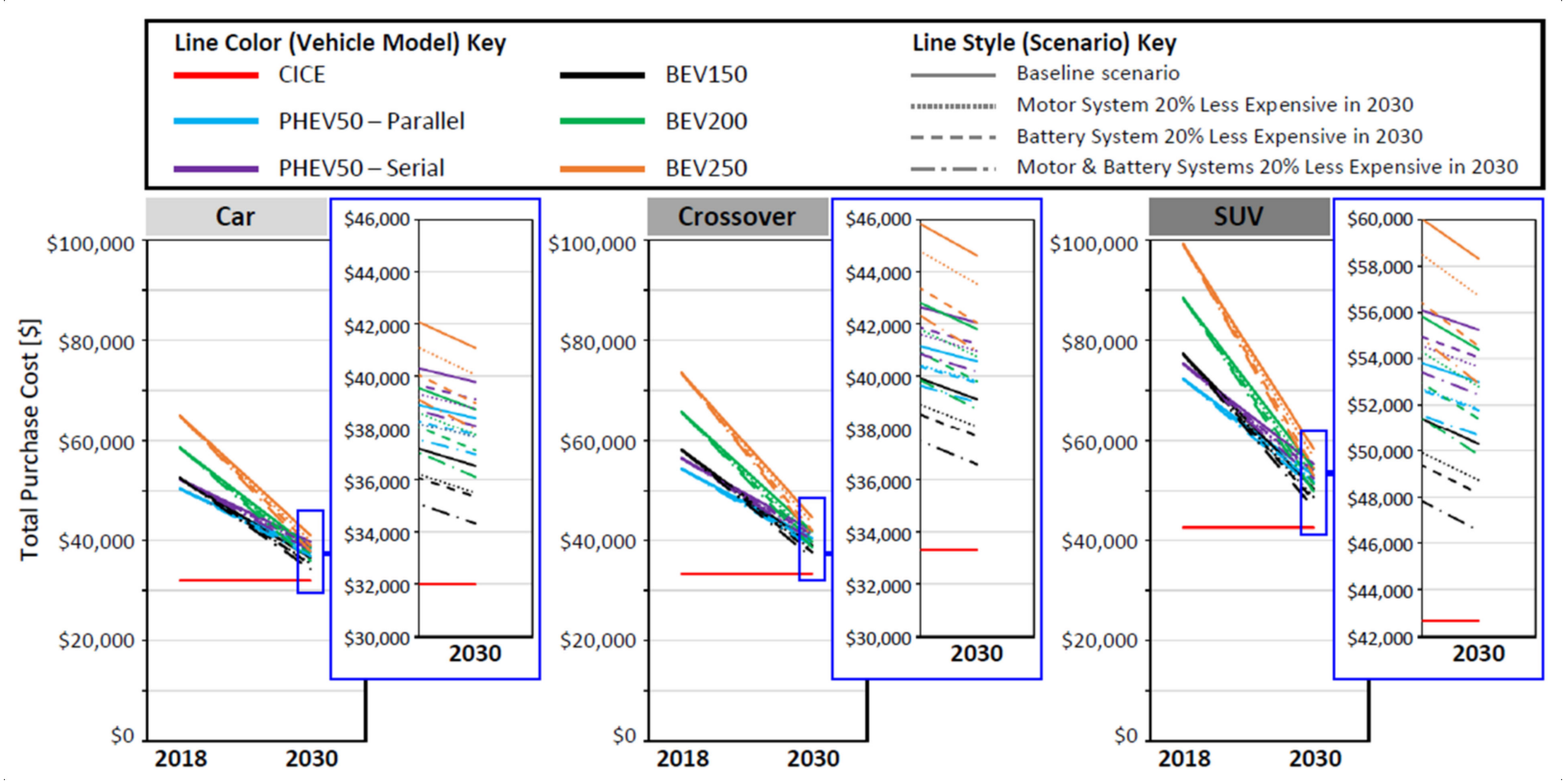

Figure 3. Purchase cost sensitivity analysis for various 2030 scenarios.

Since vehicle driving patterns and cost of gasoline affect the running cost (and by extent, TCO) but not purchase cost, the more optimistic purchase cost scenarios in current work consider: (i) the less-expensive motor system, (ii) less-expensive battery system, and (iii) less-expensive motor and battery systems, as shown in Figure 3. As a note about Figure 3, line plots are utilized for providing good visualization of the contrast between 2018 and 2030 (for example, difference in purchase cost from 2018 to 2030 for BEV250 Car is more difficult to visualize in Figure 1b) but should not be interpreted as interpolation between 2018 and 2030 (since [14] only estimates cost values for 2018 and 2030). To aid in distinction between various scenarios, Figure 3 also includes zoom-in magnification (area surrounded by blue boxes in Figure 3) of the 2030 cost estimates. The main observation from Figure 3 is that even in the most optimistic cost of technology scenarios (both Motor and Battery systems at $20 \%$ less than baseline), the least purchase cost of a PEV (which is BEV150 in 2030) is at approximately $\$ 2300, \$ 3200$ and $\$ 3800$ more than CICE for the size categories of Car, Crossover and SUV, respectively.

Aside from baseline scenario, Figure 4 shows TCO scenarios for different vehicle groups, with (i) optimistic 2030 technology costs, and (ii) optimistic 2030 technology costs along with more expensive gasoline. The main observations from Figure 4 include:

- Due to efficiency improvements (per assumptions in [12]), there is no significant change in the TCO of CICEs between 2018 and 2030 in the baseline scenario (solid red lines in Figure 4) despite the increase of gasoline price from \$2.81/gal to \$3.36/gal. In the more expensive gasoline scenario $(\$ 5.1 / \mathrm{gal})$, however (dashes with double-dot red lines in Figure 4), there is a noticeable increase in the TCO of CICEs across all vehicle usage patterns for all size categories.

- $\quad$ Per Table 1, all PEVs have some amount of equivalent gasoline usage (except BEVs in most-urban driving, which have zero or near-zero equivalent gasoline). As such, the line plots in Figure 4 corresponding to optimistic technology costs (dash-dot lines) have lower cost values than the line plots for optimistic technology costs along with higher gasoline price (dash double-dot lines in Figure 4), except for Figure 4c, where the dashdot and dash double-dot lines overlap for BEVs. Thus, when making observations via Figure 4, comparisons should be among different line colors (powertrains) for same line style (scenario). Furthermore, there is no dash-dot red line in Figure 4 since the more optimistic battery and more technology cost scenarios have no effect on the TCO of CICE. 
- Driving patterns can have a large impact on the TCO of PEVs, and especially BEVs. BEV150 has the lowest 2030 TCO among BEVs for the most urban driving (Figure 4c), BEV200 has the lowest $2030 \mathrm{TCO}$ among BEVs for population average (Figure 4a), while BEV250 has the lowest 2030 TCO among BEVs for the least urban driving (Figure 4b).

- Despite PEVs having high UF (less gasoline usage) for the most-urban vehicles group (Table 1), this sub-population of vehicles have low annual VMT (Table 1), resulting in the running cost savings not being enough to offset the difference in purchase cost minus resale value for any of the PEVs in Figure $4 \mathrm{c}$ when considering any samescenario comparison (i.e., solid-line to solid line, dash-dot to solid red line or dash double-dot to dash-double dot) for any of the vehicle size categories.

- For the population-average driving pattern as represented by all CHTS vehicle samples (Figure 4a), the 2030 TCO of PHEVs can be lower than CICEs for all vehicle size categories when gasoline price is high. If gasoline price were to stay at the baseline 2030 prediction, it would take the more optimistic technology scenario for only the parallel-drive PHEV50 to barely break even with CICE (comparing dash-dot blue line with solid red line in Figure 4a) in the Car and Crossover size categories, but not SUV.

- Despite lower UF (more gasoline usage) for the least-urban vehicles group (Table 1), high annual VMT (VMT) sets the 2030 TCO of PHEVs at a sizable margin below CICEs for the high gasoline price scenario (dash double-dot blue and purple lines compared to dash double-dot red line in Figure $4 \mathrm{~b}$ ) across all vehicle size categories. For this group of vehicles, PHEVs can reach break-even with CICE in terms of TCO even in the baseline scenario (solid blue and purple lines compared to solid red line in Figure 4b) for Car and Crossover size categories.

The overall summary of the sensitivity analysis is that there exist some sub-populations of vehicle users and/or optimistic scenarios for-which the TCO of some PEVs can break even or become lower than the TCO CICEs by 2030 without incentives. However, without incentives, none of the modelled PEVs are expected to break-even with CICEs before 2030 in terms of purchase cost. It is important to note, however, that while purchase cost and/or TCO may be indicative of vehicle competitiveness, real human decision-making for vehicle choice (example of such work may be found in [28]) is a more complex process and is beyond the scope of the current work.

Sales of PEVs have mostly seen steady growth in the US [7] in the presence of various incentive programs that include tax credits [8], purchase rebates [9], as well as other perks such as access to high-occupancy vehicle (HOV) highway lanes [10]. Much speculation exists on when/whether PEVs would/could be cost competitive in the mass market without any incentives. Two important metrics in assessing cost competitiveness include: (i) purchase cost to a prospective owner, and (ii) total cost of ownership (TCO), which also factors in a resale value and running costs throughout a period of ownership. While [11] shows that reducing GHG emissions via PEVs comes at an increased cost compared to CICEs, [12] predicts that BEVs could reach TCO parity, and even purchase cost parity with CICEs by the mid-2020s. In general, bottom-up approaches for cost estimation follow the same framework of: (i) estimation of the cost of technologies/components to manufacture the vehicle, (ii) estimation of mark-ups pertaining to vehicle acquisition, and (iii) estimation of costs and/or credits throughout the vehicle ownership period. Depending on assumptions and/or cost forecasting models of various components, similar frameworks could lead to very different results. To help resolve some of those uncertainties in a transparent manner, the authors conducted an extensive review / critique of the literature and publicly available data sources [13], with the culmination of the work open-sourced into a publicly-accessible spreadsheet [14]. 


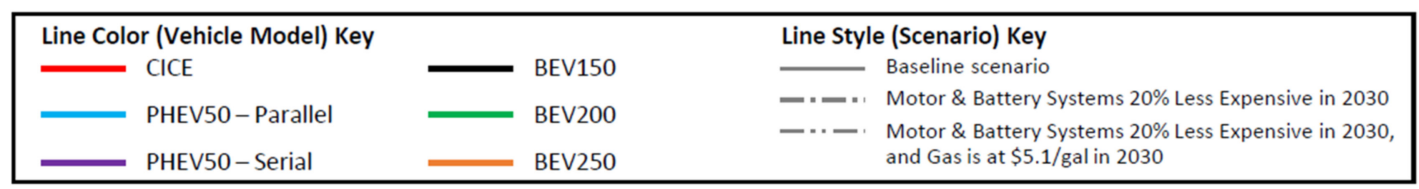

(a) Vehicle usage pattern: All CHTS dataset
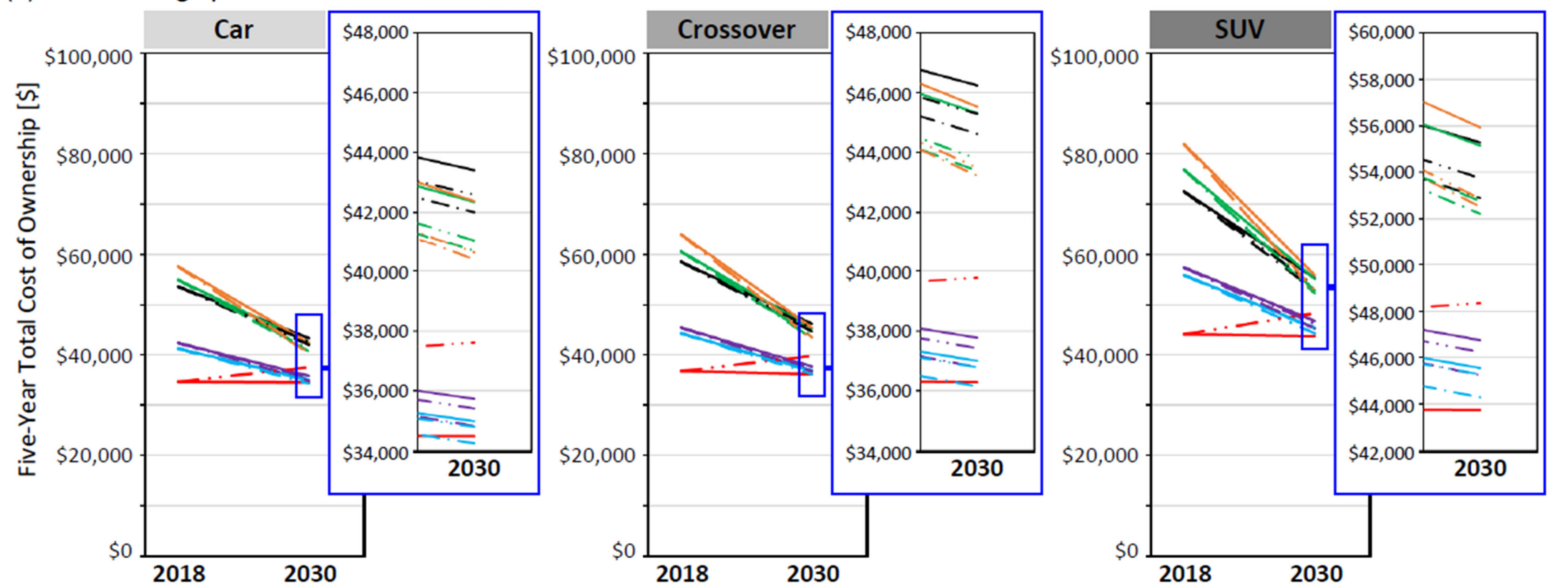

(b) Vehicle usage pattern: 29\% Least-Urban Vehicles in CHTS dataset
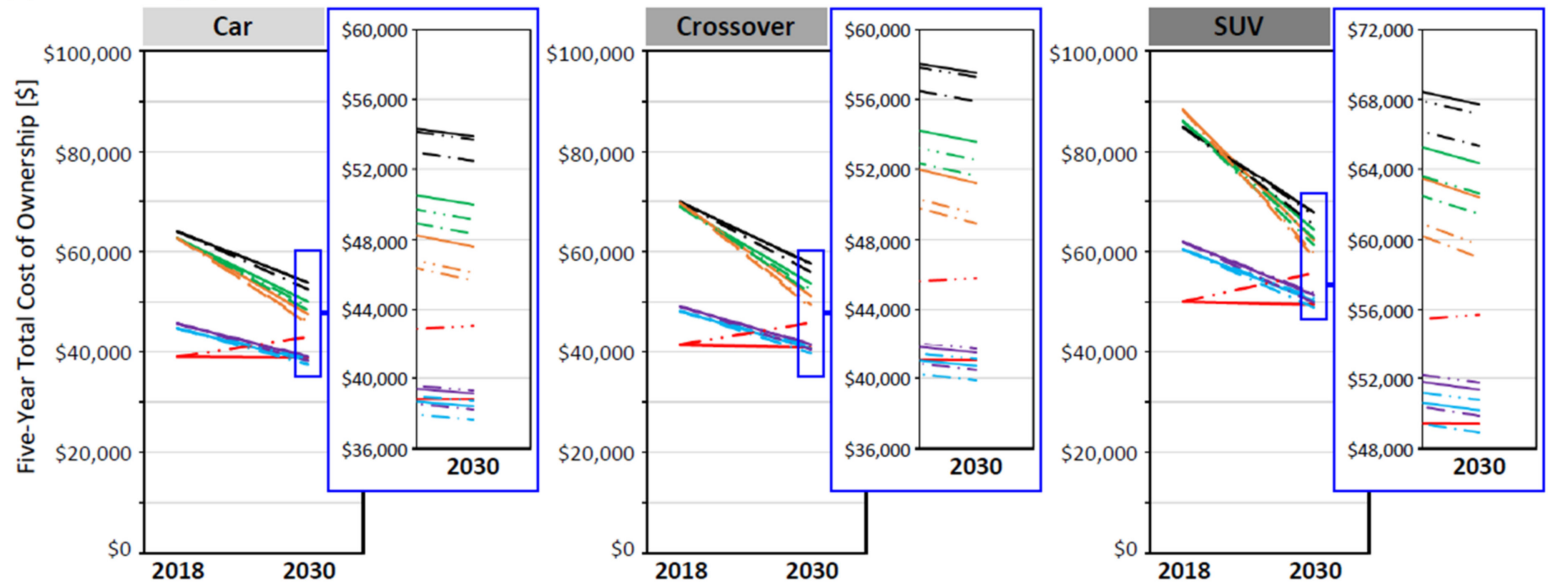

(c) Vehicle usage pattern: 29\% Most-Urban Vehicles in CHTS dataset
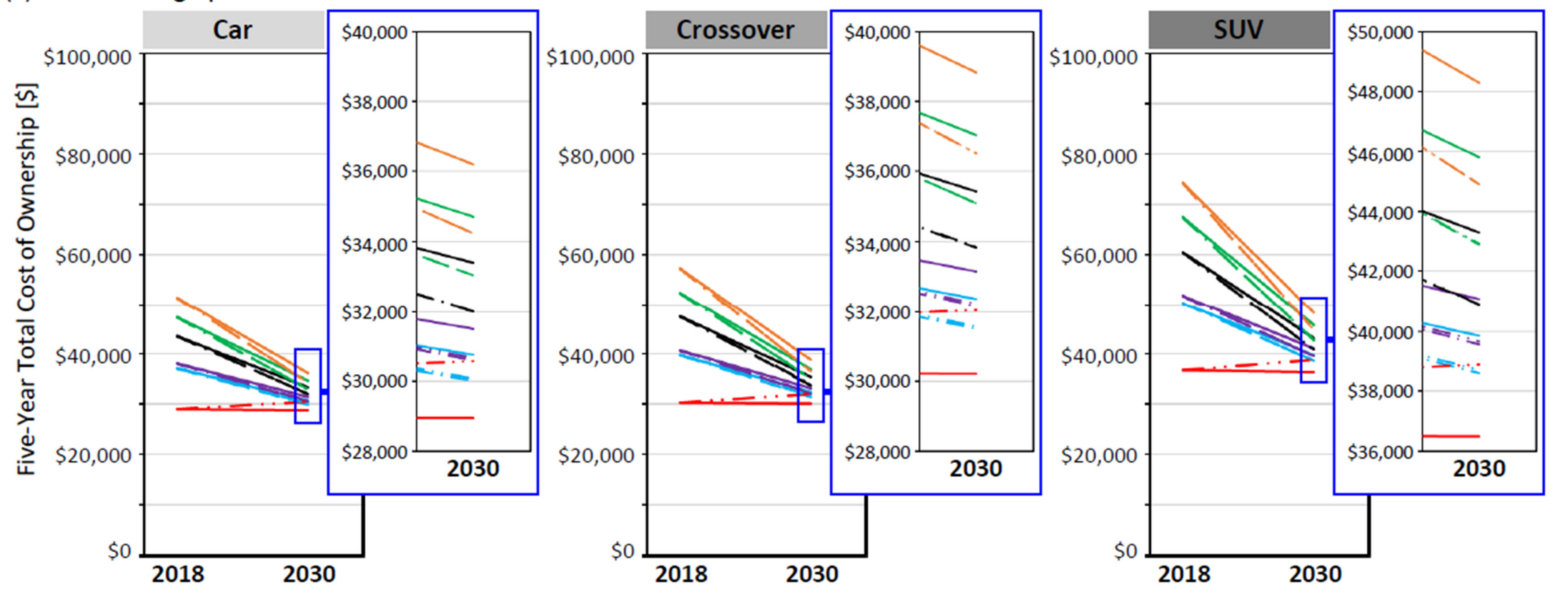

Figure 4. Total cost of ownership for different vehicle usage patterns, with sensitivity analysis for 2030 scenarios. (a) Driving patterns from all CHTS dataset (b) Less-urban driving patterns obtained from the $29 \%$ least urban vehicles in CHTS dataset (c) More-urban driving patterns obtained from the $29 \%$ most urban vehicles in CHTS dataset. 


\title{
4. Conclusions
}

\subsection{Summary of Findings}

A bottom-up cost modeling approach is adopted in this work, along with a review and critique of the literature and public data sources, for estimation of the purchase cost and TCO of three vehicle size categories of CICE, as well as several PEVs. The cost model is implemented in a publicly open-source spreadsheet and was utilized to generate a baseline scenario for 2018 and 2030, as well as a sensitivity analysis for more optimistic/favorable assumptions for PEVs in 2030. Results of the sensitivity analysis show:

- Without subsides or incentives, parity in the purchase cost between PEVs and CICEs is unlikely to happen before 2030 .

- TCO may reach break-even without incentives by 2030 under some PEV-favorable conditions such as lower costs of batteries and motors compared to the baseline prediction, along with higher gasoline price and/or longer annual distance travelled (thus allowing for savings during use phase to make up for the differences in upfront purchase cost).

\subsection{Research Development}

Future extensions of this work may include higher granularity in the sensitivity analysis by considering TCO at the individual household-level (as opposed to partitioning the population into three groups), and/or considering different vehicle ownership models such as leasing and/or different ownership period. Also of interest for future studies are high annual VMT applications, such as when vehicles are used in ride-hailing service (e.g., Uber and Lyft) applications.

Author Contributions: Conceptualization, K.H. and K.P.L.; methodology, all authors; software, all authors; validation, all authors; formal analysis, all authors; investigation, all authors; resources, all authors; data curation, all authors; writing—original draft preparation, K.H. and K.-C.C.; writingreview and editing, K.P.L. and K.-C.C.; visualization, K.H. and K.-C.C.; supervision, K.P.L.; project administration, all authors. All authors have read and agreed to the published version of the manuscript.

Funding: This research received no external funding.

Acknowledgments: The authors would like to express thanks to Arthur Yip and Jeremy Michalek from Carnegie Mellon University, as well as Aaron Brooker and Jeff Gonder from NREL for insightful discussions and thoughtful critique of some of the literature cited in this work.

Conflicts of Interest: The authors declare no conflict of interest.

\section{List of Abbreviations}

\author{
AAA American Automobile Association \\ BEV Battery (only) Electric Vehicle \\ CHTS California Household Travel Survey \\ CICE Conventional Internal Combustion Engine vehicle \\ EIA (United States) Energy Information Administration \\ HOV High-Occupancy Vehicle \\ OEM Original Equipment Manufacturer \\ PEV Plug-in Electric Vehicle \\ PHEV Plug-in Hybrid Electric Vehicle \\ SUV Sports Utility Vehicle \\ TCO Total Cost of Ownership \\ UF Utility Factor \\ VMT Vehicle Miles Travelled
}




\section{References}

1. US Department of Energy. Vehicle Technologies Program. 2011. Available online: http://energy.gov/sites/prod/files/2014/05/ f15/52723.pdf (accessed on 1 October 2019).

2. Axsen, J.; Kurani, K.S.; McCarthy, R.; Yang, C. Plug-in hybrid vehicle GHG impacts in California: Integrating consumer-informed recharge profiles with an electricity-dispatch model. Energy Policy 2011, 39, 1617-1629. [CrossRef]

3. Karabasoglu, O.; Michalek, J. Influence of driving patterns on life cycle cost and emissions of hybrid and plug-in electric vehicle power trains. Energy Policy 2013, 60, 445-461. [CrossRef]

4. Yuksel, T.; Tamayao, M.-A.M.; Hendrickson, C.; Azevedo, I.M.L.; Michalek, J.J. Effect of regional grid mix, driving patterns and climate on the comparative carbon footprint of gasoline and plug-in electric vehicles in the United States. Environ. Res. Lett. 2016, 11, 44007. [CrossRef]

5. Laberteaux, K.; Hamza, K.; Willard, J. Optimizing the electric range of plug-in vehicles via fuel economy simulations of real-world driving in California. Transp. Res. Part D 2019, 73, 15-33. [CrossRef]

6. Jenn, A.; Azevedo, I.L.; Michalek, J.J. Alternative-fuel-vehicle policy interactions increase U.S. greenhouse gas emissions. Transp. Res. Part A Policy Pract. 2019, 124, 396-407. [CrossRef]

7. Electric Drive Transportation Association. Electric Drive Sales Dashboard. 2019. Available online: http:/ / www.electricdrive.org/ index.php?ht=d/sp/i/20952/pid/20952 (accessed on 1 October 2019).

8. US Department of Energy. Federal Tax Credits for New All-Electric and Plug-in Hybrid Vehicles. 2016. Available online: https:/ / www.fueleconomy.gov/feg/taxevb.shtml (accessed on 1 January 2016).

9. California Clean Vehicle Rebate Program. 2015. Available online: https:// cleanvehiclerebate.org/eng (accessed on 1 January 2016).

10. California Environmental Protection Agency. 2012. Available online: https://ww2.arb.ca.gov/resources/documents/historicalalternative-fuels-vehicles-incentive-programs (accessed on 8 March 2021).

11. Traut, E.; Hendrickson, C.; Klampfl, E.; Liu, Y.; Michalek, J.J. Optimal design and allocation of electrified vehicles and dedicated charging infrastructure for minimum lifecycle greenhouse gas emissions and cost. Energy Policy 2012, 51, 524-534. [CrossRef]

12. Lutsy, N.; Nicholas, M. Update on Electric Vehicle Costs in the United States through 2030. Available online: https://theicct.org/ publications / update-US-2030-electric-vehicle-cost (accessed on 1 October 2019).

13. Hamza, K.; Laberteaux, K.; Chu, K.-C. On Modeling the Total Cost of Ownership of Electric and Plug-in Hybrid Vehicles; Technical Paper; SAE International: Warrendale, PA, USA, 2020.

14. Shared folder on Google Drive. 2020. Available online: https://drive.google.com/drive/folders/15aRR8WrrVV6ttqxSJXfcM8 INf0WrTgxK? usp=sharing (accessed on 3 November 2019).

15. UBS. UBS Evidence Lab Electric Car Teardown—Disruption Ahead? 2017. Available online: https://neo.ubs.com/shared/d1 ZTxnvF2k/ (accessed on 1 October 2019).

16. Anderman, M. The xEV Industry Insider Report. 2019. Available online: https://www.totalbatteryconsulting.com/industryreports/xEV-report/Extract-from-the-xEV-Industry-Report.pdf (accessed on 1 November 2019).

17. US Department of Energy. Fuel Economy Guide. 2019. Available online: https://www.fueleconomy.gov/feg/printGuides.shtml (accessed on 1 January 2019).

18. National Research Council. Transitions to Alternative Vehicles and Fuels; The National Academic Press: Washington, DC, USA, 2013.

19. National Renewable Energy Laboratory. Future Automotive Systems Technology Simulator. 2018. Available online: http: / / www.nrel.gov/transportation/fastsim.html (accessed on 1 October 2019).

20. National Renewable Energy Laboratory. 2010-2012 California Household Travel Survey. 2013. Available online: https://www nrel.gov/transportation/secure-transportation-data/tsdc-california-travel-survey.html (accessed on 1 October 2019).

21. Hamza, K.; Laberteaux, K.P. A Cluster Analysis Study of Opportune Adoption of Electric Drive Vehicles for Better Greenhouse Gas Reduction. In Proceedings of the ASME 2016 International Design Engineering Technical Conferences and Computers and Information in Engineering Conference, Charlotte, NC, USA, 21-24 August 2016.

22. U.S. Energy Information Administration. Weekly Retail Gasoline and Diesel Prices. 2019. Available online: https://www.eia. gov /dnav / pet/pet_pri_gnd_dcus_nus_a.htm (accessed on 1 November 2019).

23. EIA. Annual Energy Outlook. 2019. Available online: https://www.eia.gov/outlooks/ieo/pdf/ieo2019.pdf (accessed on 1 November 2019).

24. US Department of Transportation. Summary of State Motor-Vehicle Registration Fee Schedules. 2019. Available online: https:/ / www.fhwa.dot.gov/ohim/hwytaxes/2001/pt11.htm (accessed on 1 October 2019).

25. Sayles, J.; The Most Expensive States to Own a Car. U.S. News, 7 January 2020. Available online: https:/ / cars.usnews.com/carstrucks/most-expensive-states-to-own-a-car(accessed on 1 October 2019).

26. American Automobile Association. Your Driving Costs. 2019. Available online: https://exchange.aaa.com/wp-content/uploads/ 2019/09/ AAA-Your-Driving-Costs-2019.pdf (accessed on 1 November 2019).

27. Kelly Blue Book. 2019. Available online: https://www.kbb.com/ (accessed on 1 November 2019).

28. Helveston, J.P.; Liu, Y.; Feit, E.M.; Fuchs, E.; Klampfl, E.; Michalek, J.J. Will subsidies drive electric vehicle adoption? Measuring consumer preferences in the U.S. and China. Transp. Res. Part A Policy Pract. 2015, 73, 96-112. [CrossRef] 